\title{
Análise topológica e dinâmica das vias públicas da cidade de Fortaleza
}

\author{
Francilio Araújo da Costa* Michael Souza \\ Departamento de Estatística e Matemática Aplicada, Centro de Ciências, UFC \\ 60455-760, Fortaleza, Ceará, Brasil \\ E-mail: francilioaraujo@gmail.com,_souza.michael@gmail.com
}

\author{
Ascânio Dias de Araújo \\ Departamento de Física, Centro de Ciências, UFC \\ 60455-900, Fortaleza, Ceará, Brasil \\ E-mail: ascanio@fisica.ufc.br
}

\begin{abstract}
RESUMO
O crescimento acelerado e desordenado das cidades juntamente com o recente aumento das vendas de veículos têm impactado consideravelmente o tempo e os custos de deslocamento nas vias públicas. No presente trabalho, analisaremos a malha viária de cidade de Fortaleza tanto do ponto vista topológico quanto dinâmico. Uma análise precisa da estrutura e das interações entre indivíduos em uma malha viária pode auxiliar no aumento e na manutenção da eficiência das malhas viárias, diminuindo a ocorrência, duração e extensão dos engarrafamentos.

A análise topológica ajuda a entender como a geometria da rede influi na movimentação dos indivíduos. Malhas bem construídas podem ter índices menores de engarrafamentos e propiciar maior mobilidade dos indivíduos. Malhas mal construídas propiciam engarrafamentos frequentes que podem gerar um efeito dominó, prejudicando várias localidades da rede em um curto espaço de tempo.

Já a análise dinâmica nos permite entender como o comportamento dos indivíduos pode prejudicar a eficiência da malha. Nesta análise, consideramos dois tipos de equilíbrio: o equilíbrio social e o equilíbrio de Nash. O equilíbrio social é caracterizado pela distribuição dos percursos (caminhos) de tal forma que o tempo médio seja minimizado. O equilíbrio de Nash por lado mostra qual a distribuição percursos quando cada indivíduo toma o melhor caminho para si. O equilíbrio de Nash mostra a distribuição dos caminhos quando os indivíduos tomam decisões egoístas. De posse dos custos destes dois equilíbrios podemos calcular o preço da anarquia (POA, do inglês "Price of Anarchy") que mensura a ineficiência da gestão descentralizada. Em outras palavras o POA aponta qual o impacto sobre a eficiência da malha caso os indivíduos passem de uma estratégia solidária para uma estratégia egoísta. Quanto maior o POA menor será a eficiência da malha.

Neste artigo, analisamos a topologia da cidade de Fortaleza através de um estudo comparativo com a topologia de outras cidades como Barcelona, Brasília, Cairo, Los Angeles, Nova Delhi entre outras. Já os resultados dinâmicos são comparados a modelos teóricos e a outras cidades como Boston, Londres e Nova Iorque.
\end{abstract}

Palavras-chave: Redes Complexas, Preço da anarquia, eficiência de redes de transportes

*Bolsista de Iniciação Científica PIBIC/CNPq, Helpu al vi, vin helpos Di'! 


\section{Referências}

[1] A. Cardillo, Structural properties of planar graphs of urban street patterns, Physical Review E, v. 73 n. 6 (2006) p. 066107.

[2] M.T. Gastner, The spatial structure of networks, The European Physical Journal BCondensed Matter and Complex Systems, v. 49 n. 2 (2006) p. 247-252.

[3] T. Roughgarden, The price of anarchy is independent of the network topology, Journal of Computer and System Sciences, v. 67 n. 2 (2003) p. 341-364.

[4] H. Youn, Price of anarchy in transportation networks: Efficiency and optimality control, Physical review letters, v. 101 n. 12 (2008) p. 128701. 